When the symptomatology sections were analysed separately, again the majority, $42(81 \%)$, contained more positive information and all had more negative information.

A mean of 6 errors (range 0-32) were made in completing each questionary, but on only three occasions were contradictory answers given, and on two occasions two answers were given to the same question, the rest being those of simple omission of questions. In $49(94 \%)$ out of the 52 questionaries some facts were present in the notes alone, with a mean number of 7 (range 0-25) facts per set analysed. These may be construed as omissions of questions from the questionary, and the addition of a few questions is required. Furthermore, 36 (69\%) questionaries contained straight contradictions with the standard notes, with a mean of one contradiction per set analysed (range $0-5$ ). These seemed to be due to misinterpretation of what constituted a present symptom, an error which should be clarified by more careful wording of the instruction sheet.

Comparison of those questions whose meaning was reversed so that "yes" became the negative answer with those in which "yes" remained the positive answer showed no statistical difference $(P=0.5)$, and thus there was no tendency to answer "yes" indiscriminately. Analysis of the answers in each column and comparison with the expected answers in each column showed no statistical difference- that is, no tendency to answer the first, second, or third column automatically.

\section{Discussion and Conclusions}

It appears that the majority of patients $(94 \%)$ who are capable of reading and writing are also capable of completing a questionary of considerable length given a branching system such as is described. This compares well with Mayne's computer-assisted medical questionary. No antipathy appeared to be provoked except on one occasion, and the contrary was true in the majority of patients. The time taken to complete the questionary was not assessed, since the aim is to use it primarily for outpatients, the questionary being sent to the patient in advance of his outpatient appointment.

Our choice of patients for this pilot study was governed by ease of administration. It is recognized that these patients had been taken through a standard medical history on at least one occasion, and to some extent been "educated" in their symptoms. With this questionary it appears that the questions are answered "truthfully" in that there was no tendency to answer in any particular column or way. It was not felt necessary to incorporate "lie" response questions as is possibly relevant in a psychiatric questionary (Gibson, 1962).

Verification of this questionary should prove relatively easy with computer analysis, as the layout is such that a question can be altered or withdrawn, and the results of this study would suggest that such verification should be undertaken. With extension to a wider group of patients the questionary should provide useful additional information for the standard medical history, and a considerable amount of information should be obtained for further research purposes.

\section{REFERENCES}

Brodman, K., Erdmann, A. J., Lorge, I., and Wolff, H. G. (1951). f. Amer. med. Ass., 145, 152 .

Brodman, K., and van Woerkom, A. J. (1966). F. Amer. med. Ass., 197, 901 .

Eysenck, H. J., and Eysenck, S. B. G. (1964). Eysenck Personality Inventory. London.

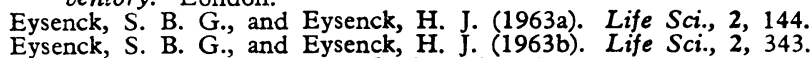

Eysenck, S. B. G., and Eysenck, H. J. (1963b). Life
Gibson, H. B. (1962). Acta physiol. (Amst.), 20, 18. Mayne, J. G., Weksel, W., and Scholtz, P. N. (1968). Mayo Clin. Proc.,
43, 1.

\title{
Hospital Scientific and Technical Services
}

The Committee on Hospital Scientific and Technical Services* was set up in July 1967 with the following terms of reference: "To consider the future organization and development of hospital scientific and technical services in National Health Service hospitals and the broad pattern of staffing required and to make recommendations." The following extracts are taken from the Committee's report, which was published on 5 December.

"Our terms of reference are wide. It seemed to us that our task was to take stock of the present position, to forecast the trends in the hospital scientific and technical services and see what implications these might have for future patterns of organization and staffing ; to consider whether a new organization and structure would be advantageous, but if so, not necessarily to recommend how such a structure could be applied to each individual part of the present service. Our report is therefore comparatively short and schematic; we have deliberately refrained from setting out in detail what should constitute the Hospital Scientific Service which we in fact recommend, or exactly which grades of staff should be included and at which level they should be incorporated.

"The members of the Committee were Sir Solty ZUCRERMAN, F.R.S. (chairman); Professor A. R. CURRIE ; Dr. R. GADDIB ; Professor J. E. RHILLINGFORD; and Professor S. SHONE.
"We were much impressed by the weight of opinion in favour of a career structure for the non-medical scientists and technicians similar to that provided by the Scientific Civil Service or Medical Research Council. It was also generally recognized that centralization of services was tending to become more necessary in the interests of efficiency, in view of the increasing cost and sophistication of equipment and the greater application of scientific techniques. Many papers recommended a grouped department of 'clinical science,' ' technological services,' 'medical science,' or 'physical science'; others favoured a grouping of physiological services in a department of 'clinical measurement.' There were few who disagreed with the view that there should be a central pool of scientific and technical str.ff who could, if necessary, be seconded from time to time for varying periods to a clinical team when required, rather than be permanently established in a clinical unit. Exclusive attachments to a clinical unit were said to result in the people concerned getting out of touch with the main stream of scientific developments, the service might have to depend on one individual, and the units were inadequately equipped or the equipment under-utilized. There were several comments on the advantages to be gained from having non-medical scientists working in departments and specialties where they are seldom found at present-for example, in the intensive care units, the diagnostic $x$-ray department, in haematology and microbiology.

"There was strong support, both from medical and non-medical organizations, for the view that the relationship between the clinician and the non-medically qualified scientist should be one of collaboration, that senior scientists should have comparable status to consultant medical staff, and that they should be members of the appropriate hospital advisory committees.

"Emphasis was laid upon the importance of continuous training and retraining of technicians in onder to encourage them to keep abreast of changing techniques. It was suggested that when training of technical staff was under the influence of a professional body or staff association, it tended to be rigid, and to reflect the ambitions of the body concerned to advance its own status rather than a desire to meet the real needs of the service. The influence of 'state negistration' in bringing order into the Professions Supplementary to Medicine was mentioned, and there were proposals that other classes of technicians should be assimilated to the present Medical Laboratory Technician staffing istructure. But several submissions iseverely criticized the rigidity of the present application of the 'state registration' provisions in preventing 
both the employment of new skills in a rapidly expanding field and the modification of training schedules to meet changing needs, and in not allowing for greater depth of training where this was desirable in specialized fields of medical laboratory technology.

\section{The Present Situation}

"The number of staff employed in these [hospital scientific] services is now about 27,000 . The numbers in the main categories are shown in Table I. A net increase of over 100 per cent. in the past 10 years, which has occurned, is high by any standand, but thene are still shortages, and it is not easy to be clear about the true need at the present time, still less to predict future needs.

TABLE I.-Number of Staff in Post in the National Health Service (England, Wales, and Scotland) Whole-time Equivalents

\begin{tabular}{|c|c|c|c|}
\hline & 1957 & 1962 & 1967 \\
\hline 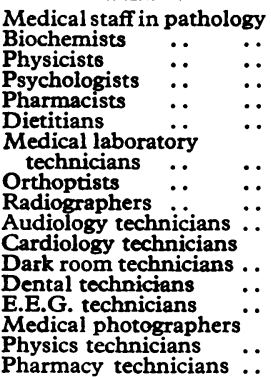 & $\begin{array}{r}866^{*} \\
220 \\
116 \\
153 \\
1,473 \\
210 \\
2,942 \\
218 \\
3,578 \\
270 \\
876 \\
261 \\
92 \\
128 \\
125 \\
-\end{array}$ & $\begin{array}{r}1,540 \\
315 \\
186 \\
231 \\
1,650 \\
222 \\
\\
6,922 \\
235 \\
3,893 \\
259 \\
411 \\
1,155 \\
337 \\
137 \\
167 \\
236 \\
1,255\end{array}$ & $\begin{array}{r}1,882 \\
521 \\
294 \\
335 \\
1,636 \\
322 \\
\\
9,657 \\
278 \\
4,914 \\
287 \\
676 \\
1,204 \\
381 \\
226 \\
241 \\
409 \\
1,593\end{array}$ \\
\hline
\end{tabular}

* Consultants and senior registrars only.

"In addition to the numbers of staff given in Table I, university departments make a significant contribution to the National Health Service. For example, some 15-20 per cent. (in whole-time equivalents) of the biochemists and physicists working for the National Health Service are employed by universities.

"Apart from the pathology element, the present system, with exceptions in some regions, is primitive and uncoordinated. It is a restrictive and exclusive arrangement in the sense that when a new development is introduced, existing departments and existing grades of staff tend neither to be ready nor able to include it within their framework. New departments may then be formed in isolation, often in improvised accommodation, with new technical classes. Many of the difficulties which hospitals have experienced in staffing their technical departments are attributable to this shortcoming.

"In some cases a non-medical scientist, if employed exclusively in a single clinical department within a hospital, may not be able to contribute to the general medical work of the hospital to the full extent of his capacity. This is unfortunate. . . Given the wider scientific environment, as now exists in some hospital centres, the scientific contribution of the non-medical graduate is every bit as vital as the scientific contribution of the medical graduate. And there should always be scope for the graduate scientist to carry out research in his department.

"We are not concerned in this report with levels of pay, and we make no recommendations on this subject. However, it is clear to us that the present status of the non-medically qualified graduate scientist is often subondinate to that of the doctor, even where their professional responsibilities imply a comparable standing. This has led to a shortage of high quality graduate scientists in the hospital servioe, a situation which has been made worse by the fact that administrative and scientific control of laboratories has seldom been given to non-medical soientists.

"The management, operation and servicing of sophisticated equipment, whether in the laboratory, operating theatne or wands, is a scientific and technical function. At present, because of the lack of the neoessary scientific and technical service, these tasks often fall to clinicians and nurses, diverting them from the exercise of their proper duties. The deployment of such equipment and, even more, its operation, should not have to be the concern of the clinician.

\section{A Hospital Scientific Service}

"We recommend that oertain specialties should be recognized as forming the basis of a Hospital Scientific Service which, while remaining an integral part of the whole hospital service, would be subject to special administrative and organizational arrangements. . . . At the outset the Servioe should include the following specialties: clinical biochemistry, computer science and statistics, genetics, haematology and blood transfusion, immunology, medical microbiology, morbid anatomy and histopathology, physics with biomedical engineering, nuclear medicine and physiological measurement.

"We suggest that radiologists should continue to form pant of the hospital clinical services, but we necommend that the technical staff, such as radiographers and darkroom technicians, and the technical staff of other clinical departments not in the scientific service, such as cardiology and dental surgery, be assimilated to the new staffing structure. Career planning in consultation with the heads of the departments should be the responsibility of the scientific servioe. Scientific supervision of the equipment of these departments should also be the responsibility of the scientific service in association with medical colleagues.

"The professional staff in the Hospital Scientific Service should have two career structures. The medical staff should normally remain, as at present, in the hospital medical staff istructure. Science graduates should follow the new parallel scientific staft struoture, which we recommend. . .

"In our study of the scientific and technical work performed in hospitals we have identified four broad functional levels according to the education and training normally required, the knowledge and experience that have to be acquired, and the responsibilities that ane carried. We recommend that for non-medical scientists and technical stafi these four classes should be adopted as a framework, and that within each class there should be such grades as might be found necessary.

"The four classes are:

(a) Scientific Officer. Normally recruited from graduates with 1st or 2nd Class Honours degrees or equivalent qualifications.
Chartered engineers and sometimes persons with medical qualifications will also belong to this class. There should be opportunity for direct appointment to higher grades for scientists with appropriate experience outside the National Health Service.

(b) Technical Officer. Qualifications of the level of the Higher National Certificate. Some members of the class may be graduates.

(c) Technical Assistant. Training will normally include practical training, generally provided in-service, and complementary further education through courses for higher qualifications including those leading to promotion to the Technical Officer class.

(d) Technical Aide. No age limits or special qualifications. The members of this class will have the qualities required for simple routine procedures, care of equipment and other work requiring experience of hospital procedures.

Training would normally be in-service and promotion by experience and length of service.

"We recommend that National Hospital Scientific Counoils be set up in England and Wales and in Scotland to advise on the organization and development of the Hospital Scientific Service. .... The Regional Hospital Board (in collaboration with the Board of Governors where appropriate in England and Walles) should be responsible for planning the scientific services of the negion, including the provision of regional centres, accommodation and the larger items of equipment. . . . We think that most negions would find it an advantage to designate a regional scientific centre which should be in a hospital, and not on an isolated site. Such a centre would also provide the scientific services of that hospital.

"The Regional Hospital Board should have a Regional Scientific Advisory Committee which should include medical and nonmedical scientists with functions corresponding to those of the Medical Advisory Committee. Each Regional Hospital Board in England and Wales should have on its staff a Regional Scientist (medical or non-medical). He should be responsible for advising the Board on the planning of the scientific services in consultation with the Senior Administrative Medical Officer and should have the same status as other senior officers of the Board.

"Subject to our other recommendations, the district hospital authority should be responsible for the day-to-day management of the hospital scientific servioes and for the appointment of scientific and technical staff in the Scientific Service within an establishment agreed with the Regional Hospital Board.

"The central proposal in the Minister of Health's Green Paper is that the network of National Health Service authorities in England and Wales, viz., Regional Hospital Boards, Hospital Management Committees, Boards of Governors and Executive Councils should be replaced by a single tier of anea authorities, possibly numbering forty to fifty in all, and each responsible for all the health services in its area. If a system of this kind is established, responsibility for the functions which we have proposed that Regional Hospital Boards should fulfil in a Hospital Scientific Service will fall to the lot of the area authorities, as indeed will the functions here proposed for Hospital Management Committees. Some services may, however, be more efficiently provided by two or three area authorities making joint arrangements in the way proposed in paragraph 74 of the Green Paper." 